\title{
Nonlinear Finite Element Analysis of Shotcrete Lining Reinforced with Steel Fibre and Steel Sets
}

\author{
Jeong Soo Kim, Moon Kyum Kim, and Han Kyu Yoo
}

\begin{abstract}
This paper deals with a shotcrete lining with steel sets. The nonlinear analyses of a reinforced shotcrete lining are performed by using fiber beam-column element, which is a forced based element on the Euler-Bernoulli beam theory. The constitutive model is developed to describe the tensile behavior of shotcrete material reinforced with steel fibre. The finite element models of shotcrete lining with steel fibre and $\mathrm{H}$-section reinforcements are created. The numerical results are compared with results of 3 point flexural tests. The proposed approach shows that it can estimate the shotcrete lining with steel fibre and reinforcements approximately. It is expected to be more improved if a refined tension constitutive model is used.
\end{abstract}

Index Terms-Fiber beam-column element, nonlinear analysis of NATM tunnel lining, Steel fibre reinforced shotcrete, and Steel supports.

\section{INTRODUCTION}

NATM has been widely applied in construction of tunnel and other underground excavation all over the world since 1960 's. As shotcrete and rock bolts are used generally as the primary support during tunnel excavation, most designs and researches of tunnel supports focus on each of them. However, Steel supports are often used to reinforce the stability at the excavation face with bad conditions such as blocky or deformable ground. Steel supports not only have advantages of deriving the ductile behavior of shotcrete lining under ultimate loadings but also increase the load capacity of a composite arch before hardening of shotcrete lining fully develops.

Recently, it tends to consider the load capacity of steel sets and composite behavior of steel fibre reinforced shotcrete with steel sets in an analysis or design of the tunnel lining. Several experimental and analytical researches are performed to investigate that steel supports are taken the load from ground as compared with shotcrete and how a shotcrete lining with steel supports behaves as a composite. Leung et al. [1] compared properties of wet-mixed fiber reinforced shotcrete and fiber reinforced concrete. They conclude that data on fiber reinforced concrete can be applied for shotcrete as initial guideline. Moon et al. [2] examine that how much the H-section steel rib of steel-shotcrete composite members under axial and flexural loading takes external loads. Park et el. [3] performed flexural tests of steel fibre shotcrete beam

Manuscript received March 16, 2013; revised July 2, 2013.

The authors are with Yonsei University, Seoul, 120749, South Korea, (e-mail: coffee1210@yonsei.ac.kr, applymkk@yonsei.ac.kr, with different configuration of reinforcements such as $\mathrm{H}$-section steel beam, steel bar. They asserted steel bar can be used as steel supports based on their experimental results, instead of $\mathrm{H}$-section steel and lattice girder. Although these researches provide practical knowledge on behaviors of a steel-shotcrete composite, an experimental approach has limitations of estimating behaviors of a shotcrete lining with various mix conditions and types of reinforcements.

Carranza-Torres et al. [4] considered a lining as an equivalent section consisting of shotcrete and steel sets. After estimating internal forces of a lining with equivalent section by the structural analysis, they determined load that steel sets is taken by considering proportion of axial and flexural stiffness of steel sets to shotcrete lining. Rodriguez et el. [5] developed the analytical expression for the characteristic curve of a support based on yielding steel ribs. These approaches are useful for the preliminary design and reasonable in the linear elastic range. However, they are impossible to describe a shotcrete lining, which indicate obviously the nonlinear behavior. They also have the limitation considering the shotcrete lining as a 'real' composite because the stiffness of shotcrete lining with steel sets is determined by the superposition of stiffness of steel reinforcements and shotcrete lining which are calculated independently.

Our study introduces fiber beam-column elements to estimate the nonlinear and composite behavior of a shotcrete lining reinforced by steel fibre and steel ribs. To contain tensile resistance of steel fiber reinforced shotcrete lining, the existing flexural and direct tensile test results are used to analyze a behavior of steel fibre reinforced shotcrete material, which are simplified and applied to develop the constitutive model. Based on these experimental studies, The Kent and Park model is expanded with a new tension constitutive model. The finite element models corresponding to some flexural tests are created, and then its results are compared with each other.

\section{RELATED WORKS}

\section{A. Fiber Finite Beam-Column Element}

A fiber beam-column element developed by Spacone et al. [6]-[8] has been used in many studies to perform the nonlinear analysis of RC structures under cyclic loadings. The element with a fiber section is composed of bundles of fibers, which have 1 dimension nonlinear stress-strain relations. This finite element uses force-based formulations, which help to be the fact that equilibrium between element nodal forces and section forces can be enforced exactly in an 
element when the material response is nonlinear.

Given section deformation, the section resistances such as bending moment and axial force are calculated by sum of whole fiber's internal forces. The section resistances are compared with the section forces calculated by element nodal forces. Then, the unbalanced forces, the difference between section resistance and forces, update the section residual deformation until equilibrium at the each section is satisfied. When all section points in an element are in equilibrium approximately, the element stiffness is finally determined by integration of section flexibility. The above described procedure of determining element state is indicated in Fig. 1. The notations in Fig. 1 are explained in Appendix. The structural state determination has the similar procedure of general nonlinear analysis using the Newton-Raphson algorithm.

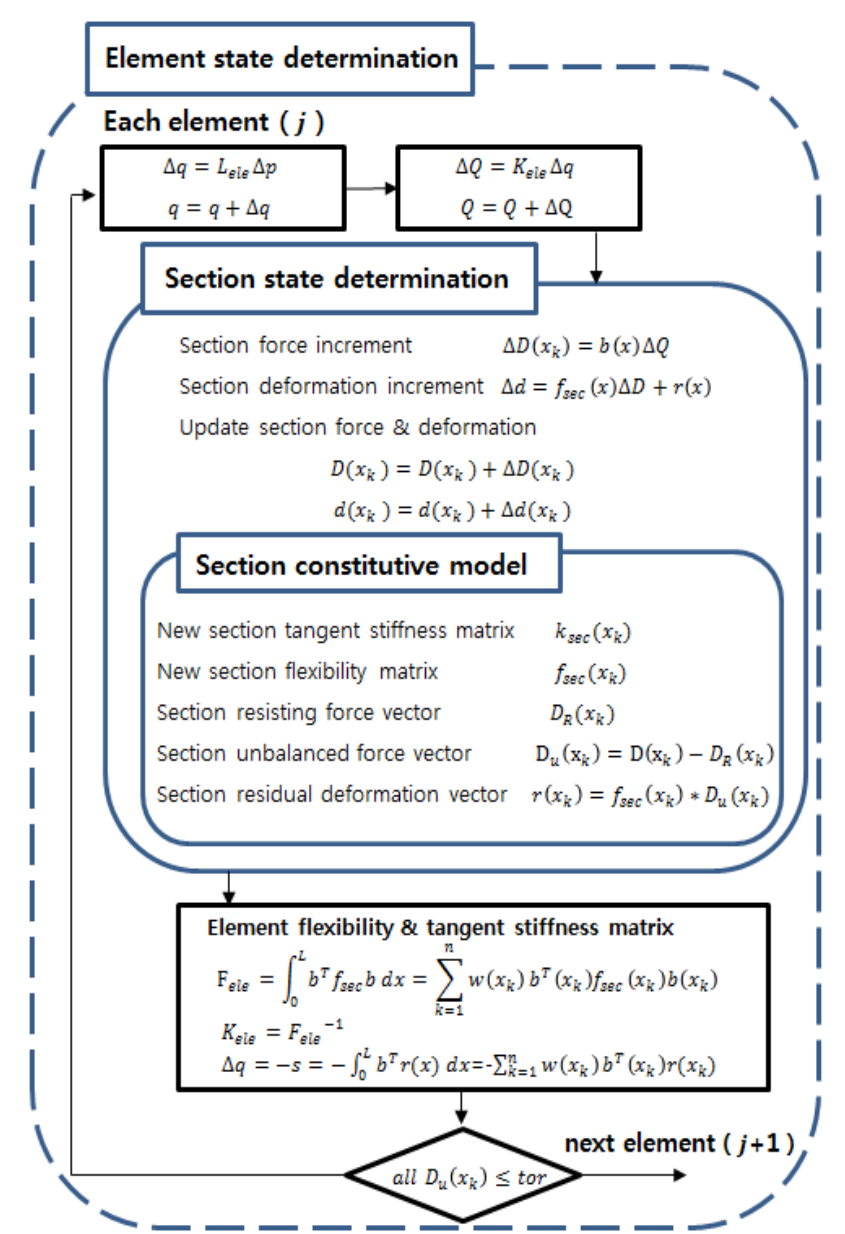

Fig. 1. Element state determination procedure [9]

\section{B. Constitutive Model for Steel Fibre Reinforced Shotcrete}

Most plane concrete models assume that residual tension strength is zero or tensile behavior is not defined. Because a shotcrete lining generally contains steel fibre, the tensile region of a shotcrete cross section has ductility and residual strength. Hence, it is needed to describe algorithmically its tensile resistance. In the results of flexural or direct tensile tests [10], [11], shotcrete specimens reinforced with steel fibre show the yield surface for tension takes parabolic shape in the hardening part and exponential shape in the softening part. The reinforced specimens also have residual strengths that are $10 \sim 35 \%$ and $50 \sim 70 \%$ of peak tensile strength in the direct tensile and flexural strength test, respectively. The residual strength is not only affected by a test method also steel fibre length, volume fraction, and shape.

In this study, the material behavior of a steel fibre reinforced shotcrete is simplified as shown in Fig. 2. The tensile stress is proportional to strain below the peak tensile strength. After that, the stress reaches the tensile residual strength that is assumed $30 \%$ of the peak tensile strength because it is presumed a fiber behaves as $1 \mathrm{D}$ in the fiber finite beam-column element method.

$$
\begin{aligned}
\sigma_{t} & =\sigma_{t}^{\prime}\left(\varepsilon_{t} / \varepsilon_{t}^{\prime}\right) & & \left(0<\varepsilon_{t} \leq \varepsilon_{t}^{\prime}\right) \\
& =\sigma_{t r} & & \left(\varepsilon_{t}^{\prime}<\varepsilon_{t} \leq \varepsilon_{t u}\right) \\
& =0 & & \left(\varepsilon_{t}>\varepsilon_{t u}\right)
\end{aligned}
$$

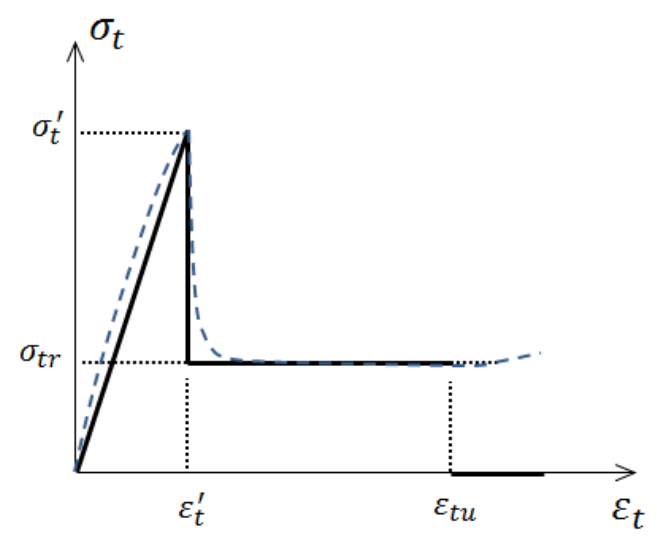

Fig. 2. Idealized tensile stress-strain relation

where $\sigma_{t}$ is tensile stress, $\varepsilon_{t}$ is tensile strain, $\sigma_{t}{ }^{\prime}$ is tensile peak strain, $\varepsilon_{t}{ }^{\prime}$ is tensile strain corresponding to the peak strength, $\sigma_{t r}$ is tensile residual stress, and $\varepsilon_{t r}$ is ultimate tensile strain. As increase of the compression strength by reinforcing the steel fibre can be ignored, as in [11], the compression behavior is modeled using by the Kent and Park model, which is

$$
\begin{aligned}
& \sigma_{c}=\sigma_{c}^{\prime}\left[2\left(\varepsilon_{c} / \varepsilon_{c}^{\prime}\right)-\left(\varepsilon_{c} / \varepsilon_{c}^{\prime}\right)^{2}\right] \quad\left(\varepsilon_{c}^{\prime}<\varepsilon_{c} \leq 0\right) \\
& =\sigma_{c}^{\prime}+\left[\left(\sigma_{c u}-\sigma_{c}^{\prime}\right)\right. \\
& \left./\left(\varepsilon_{c u}-\varepsilon_{c}^{\prime}\right)\right]\left(\varepsilon_{c}-\varepsilon_{c}^{\prime}\right) \quad\left(\varepsilon_{c u}<\varepsilon_{c} \leq \varepsilon_{c}^{\prime}\right) \\
& =\sigma_{c u} \quad\left(\varepsilon_{c} \leq \varepsilon_{c u}\right)
\end{aligned}
$$

where $\sigma_{c}$ is compressional stress, $\varepsilon_{c}$ is compressional strain $\sigma_{c}{ }^{\prime}$ is compressional peak strain, $\varepsilon_{c}{ }^{\prime}$ is compressional strain corresponding to the peak strength, $\sigma_{c u}$ is ultimate compressional stress, $\varepsilon_{c u}$ is compressional strain corresponding to the ultimate compressional stress.

\section{NUMERICAL ANALYSIS}

\section{A. Experiments}

Park et al. [3] carried out 3 points flexural tests of steel fibre reinforced shotcrete lining. To estimate the behavior and load capacity of shotcrete lining reinforced with steel fibre and steel sets, the specimens with a H-section steel 
reinforcement were tested. The cross section geometries of specimens in this study are indicated in Fig. 3. The dimension of H-section is $100 \times 100 \times 8 \times 6 \mathrm{~mm}$.

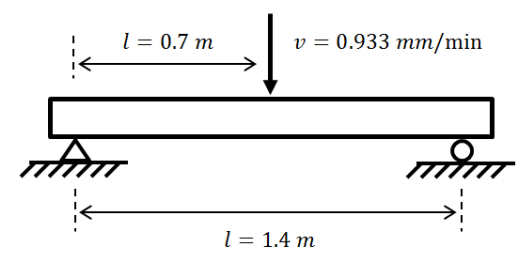

Fig. 3. (a) Geometry of 3 points flexural test of shotcrete beam
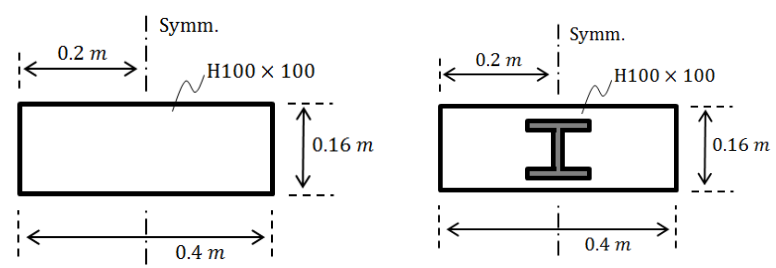

Fig. 3. (b) Cross section of shotcrete specimens-I: Not reinforced / II: Reinforced with H-section

\section{B. Numerical Models}

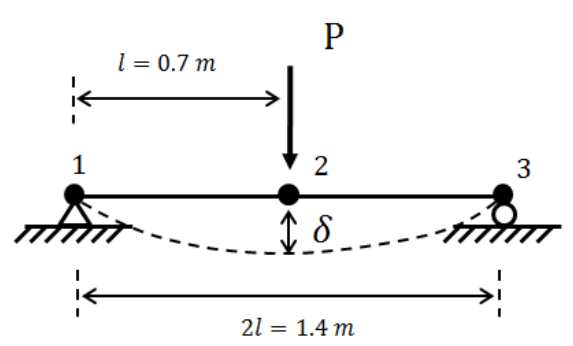

Fig. 4. (a) Finite element model

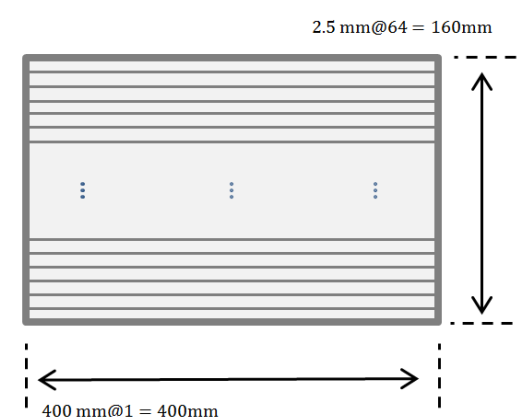

$2.5 \mathrm{~mm} @ 24+1 \mathrm{~mm} @ 16+3.5 \mathrm{~mm} @ 24=160 \mathrm{~mm}$

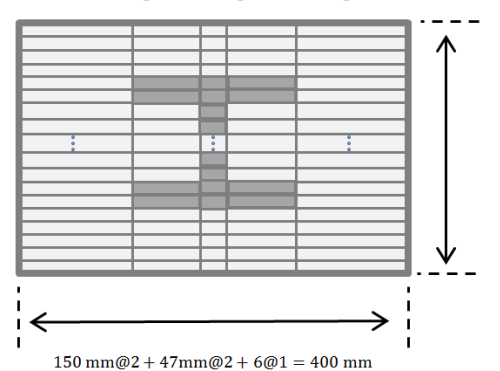

Fig. 4. (b) Fiber section of shotcrete lining-I: Not reinforced / II: Reinforced with H-section

Two simply-supported steel fibre reinforced shotcrete beams with different cross sections are modeled. A material behavior of shotcrete is described by using the Kent and Park model adding the above tensile constitutive model. Steel is modeled as the isotropic and elastic-perfect plastic material.
The properties of each material are listed in the Table I and II.

TABLE I: MATerial PRoperties USEd IN STEEl MODEL

\begin{tabular}{lcccc}
\hline \hline & \multicolumn{4}{c}{ Parameters } \\
Constitutive Model & $\sigma_{y}$ & $\varepsilon_{\mathrm{y}}$ & $\sigma_{u}$ & $\varepsilon_{u}$ \\
& $(\mathrm{MPa})$ & $(\mathrm{m} / \mathrm{m})$ & $(\mathrm{MPa})$ & $(\mathrm{m} / \mathrm{m})$ \\
\hline Elastic- perfect plasticity & 420 & 0.0021 & - & - \\
\hline \hline
\end{tabular}

TABLE II: MATERIAL PROPERTIES USED IN SHOTCRETE MODEL

\begin{tabular}{llcccc}
\hline \hline \multicolumn{2}{l}{ Constitutive Model } & \multicolumn{4}{c}{ Parameters } \\
\hline \multirow{3}{*}{$\begin{array}{l}\text { Kent \& Park } \\
+\end{array}$} & $\begin{array}{l}\text { Compression } \\
\text { part }\end{array}$ & $\begin{array}{c}\sigma_{c}^{\prime} \\
(\mathrm{MPa})\end{array}$ & $\begin{array}{c}\varepsilon_{c}^{\prime} \\
(\mathrm{m} / \mathrm{m})\end{array}$ & $\begin{array}{c}\sigma_{c u} \\
(\mathrm{MPa})\end{array}$ & $\begin{array}{c}\varepsilon_{c u} \\
(\mathrm{~m} / \mathrm{m})\end{array}$ \\
\cline { 2 - 6 } $\begin{array}{l}\text { Simplified } \\
\text { tension }\end{array}$ & Tension & $\begin{array}{c}\sigma_{t}^{\prime} \\
(\mathrm{MPa})\end{array}$ & $\begin{array}{c}\varepsilon_{t}^{\prime} \\
(\mathrm{m} / \mathrm{m})\end{array}$ & $\begin{array}{c}\sigma_{t r} \\
(\mathrm{MPa})\end{array}$ & $\begin{array}{c}\varepsilon_{t r} \\
(\mathrm{~m} / \mathrm{m})\end{array}$ \\
\cline { 2 - 6 } & part & 5 & 0.0007 & 1.2 & 0.003 \\
\hline
\end{tabular}

where $\sigma_{y}$ and $\varepsilon_{\mathrm{y}}$ are yield strength and the strain corresponding to $\sigma_{y}$ of steel, respectively.

Finite element models with two fiber section elements are created. Element stiffness is determined by using the numerical integration with 4 points Gauss-Lobatto quadrature. The section of a shotcrete beam reinforced with steel fibre and $\mathrm{H}$-section reinforcements are divided into $1 \times 32$ and $5 \times 32$ fibers, respectively. The numerical analysis is performed by our developed program, based MATLAB code, including transition of neutral axis in the section state determination. This program uses the force-based formulation by Spacone et al. applying to an Euler-Bernoulli beam type, which consider only flexural and axial deformation. Finite element models and its sections used in this study are shown in Fig. 4. To observe the strain softening behavior of shotcrete lining, the numerical tests are performed by the displacement control method.

\section{C.Numerical Results}

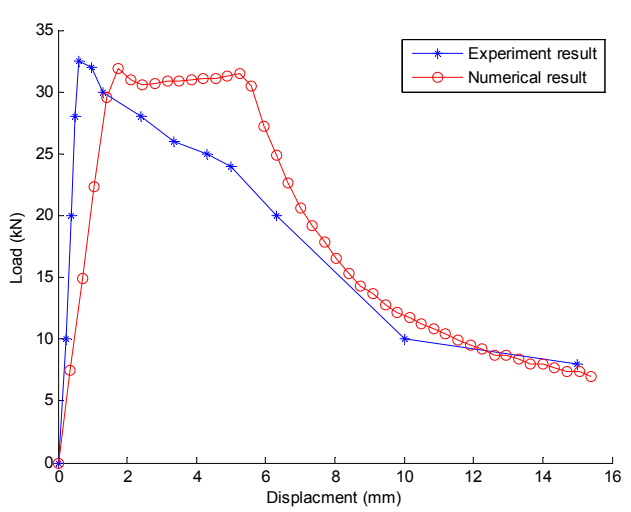

Fig. 5. (a) Comparison - Steel fibre reinforced only

Numerical results are validated by comparing with the experiments results that are measured at the mid-span of the shotcrete beams by LVDT, as shown in Fig. 5. The results of each case indicate that numerical results come close to test results. Although the tension constitutive model is simple, the used numerical approach and constitutive model show that it can be a good tool to estimate approximately steel fibre reinforced shotcrete structure. The shotcrete reinforced with 
steel fibre appears ductile behavior and is fairly agreed with test results by using the proposed approach. To examine more accurately and practically in the strain softening region, the refined algorithmic description is needed.

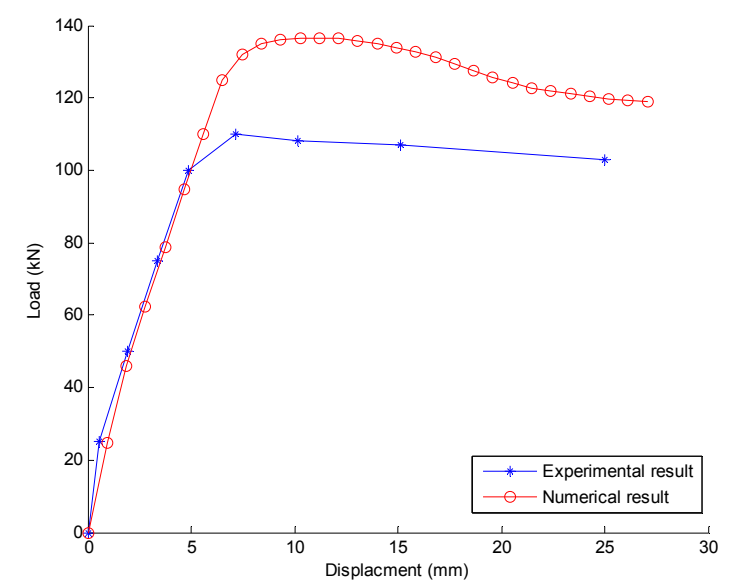

Fig. 5. (b) Comparison $-\mathrm{H}$-section steel rib reinforced additionally

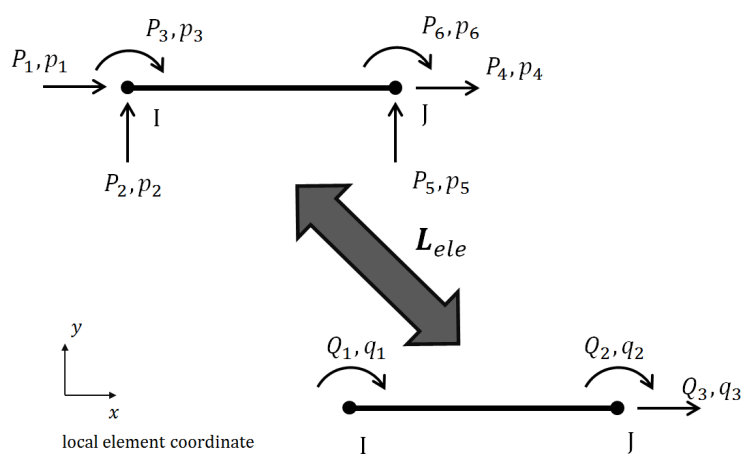

Fig. 6. Removal of rigid body modes

\section{CONCLUSION}

A new approach using a fiber finite beam-column element is introduced to estimate the nonlinear behavior of shotcrete lining. It also contains the simple algorithmic description of the behavior of shotcrete materials reinforced with steel fibre. The proposed approach is demonstrated to examine roughly the shotcrete lining by comparing with experimental data. It can predict precisely softening and ultimate behavior of shotcrete reinforced with steel fiber by using the refined constitutive model.

\section{APPENDIX}

The notations in Fig. 1, which shows the algorithm of element statement determination, are described. Notations are explained for a 2D fiber beam-column element.

Element nodal incremental displacement in local coordinate system: $\Delta \boldsymbol{p}=\left[\begin{array}{llllll}p_{1} & p_{2} & p_{3} & p_{4} & p_{5} & p_{6}\end{array}\right]^{\mathbf{T}}$

Transformation removing the rigid body modes in local coordinate system:

$$
\boldsymbol{L}_{\text {ele }}=\left[\begin{array}{cccccc}
0 & 1 / L & 1 & 0 & -1 / L & 0 \\
0 & 1 / L & 0 & 0 & -1 / L & 1 \\
-1 & 0 & 0 & 1 & 0 & 0
\end{array}\right]
$$

Element deformations: $\boldsymbol{q}=\left[\begin{array}{lll}q_{1} & q_{2} & q_{3}\end{array}\right]^{\mathbf{T}}$

Element end forces: $\boldsymbol{Q}=\left[\begin{array}{lll}Q_{1} & Q_{2} & Q_{3}\end{array}\right]^{\mathbf{T}}$

where $p_{1,} p_{2}$, and $p_{3}$ are nodal displacements at node $\mathrm{I} ; p_{4}, p_{5}$, and $p_{6}$ are nodal displacements at node $\mathrm{J} ; P_{1}, P_{2}$, and $P_{3}$ are nodal forces at node I; $P_{4} P_{5}$, and $P_{6}$ are nodal forces at node $\mathrm{J} ; q_{1}$ and $q_{2}$ represent the element end rotations relative to the chord, while $q_{3}$ denotes the overall axial deformation; $Q_{1}$ and $Q_{2}$ indicate the end moments corresponding to $q_{1}$ and $q_{2}$, and $Q_{3}$ denotes the constant element axial force; $\Delta$ means the increments of quantity.

Element Stiffness matrix: $\boldsymbol{K}_{\text {ele }}$

Internal force interpolation matrix:

$$
\boldsymbol{b}\left(x_{k}\right)=\left[\begin{array}{ccc}
x_{k} / L-1 & x_{k} / L & 0 \\
0 & 0 & 1
\end{array}\right]
$$

Element residual deformation: $\boldsymbol{s}$

Residual section deformation: $\boldsymbol{r}\left(x_{k}\right)$

Gauss-Lobatto quadrature weight: $w\left(x_{k}\right)$

Gauss-Lobatto quadrature point: $x_{k}$

\section{ACKNOWLEDGMENT}

This work was financially supported by the Nation Research Foundation of Korea (No. 2010-0026196). J.S. Kim and other authors thank the authorities concerned.

\section{REFERENCES}

[1] C. K. Y. Leung, R. Lai, and A. Y. F. Lee, "Properties of wet-mixed fiber reinforced shotcrete and fiber reinforced concrete with similar composition," Cement and Concrete Research, vol. 35, pp. 788-795, April 2003.

[2] S. H. Moon, Y. W. Shin, S. H. Kim, and H. K. Yoo, "A study on load bearing capacity of composite member with steel rib and shotcrete in NATM tunnel," KSCE, vol. 32, pp. 221-229, Sep. 2012.

[3] Y. J. Park, J. K. Lee, B. K. Noh, K. H. You, and S. D. Lee, "Flexural behavior of reinforced ribs of shotcrete for various configurations of reinforcements," Journal of Korean Society for Rock Mechanics, vol.20, pp. 169-182, June 2010

[4] C. C. Torres and M. Diederichs, "Mechanical analysis of circular liners with particular reference to composite supports. For example, liners consisting of shotcrete and steel sets," Tunnelling and Underground Space Technology, vol. 24, pp. 506-532, Sep. 2009.

[5] R. Rodriguez and M. B. Diaz-Aguado, "Deduction and use of an analytical expression for the characteristic curve of a support based on yielding steel ribs," Tunnelling and Underground Space Technology, vol. 33, pp. 159-170, Jan. 2013.

[6] E. Spacone, F. C. Filippou, and F. F. Taucer, "Fiber beam-column model for non-linear analysis of R/C frames: Part Formulation," Earthquake Engineering and Structural Dynamics, vol.25, pp. 711-725, July 1996.

[7] E. Spacone, F. C. Filippou, and F. F. Taucer, "Fiber beam-column model for non-linear analysis of R/C frames: Part Applications," Earthquake Engineering and Structural Dynamics, vol. 25, pp. 727-742, July 1996.

[8] J. P. Conte, M. Barbato, and E. Spacone, "Finite element response sensitivity analysis using force based frame models," International Journal for Numerical Method in Engineering, vol. 59, pp. 1781-1820, April 2004.

[9] J. S. Kim and M. K. Kim, "Finite element analysis of steel-shotcrete composite using the fiber beam-column element," Applied Mechanics and Materials, vol. 275-277, pp. 1359-1363, Jan. 2013.

[10] L. G. Sorelli, A. Meda, and G. A. Plizzari, "Bending and uniaxial tensile tests on concrete reinforced with hybrid steel fibers." Journal of Materials in Civil Engineering, vol. 17, pp. 519-527, Oct. 2005.

[11] S. H. Kim, I. J. Park, and J. T. Kim, "The strength characteristic of shotcrete reinforced with improved shape steel fiber," Korean Geotechnical Society, vol. 27 pp. 127-136, Dec. 2011. 


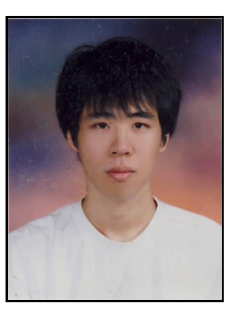

Jeong Soo Kim is currently a research assistant and $\mathrm{Ph}$. D. candidate in civil engineering and environmental engineering department of Yonsei University, Seoul, Korea. His research areas are applied mechanics, computational structure analysis, and analysis of deep tunnel constructed by NATM.

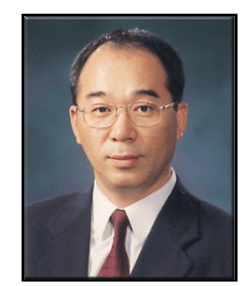

Moon Kyum Kim is working in Yonsei University at the faculty of civil and environmental engineering as a professor. His research interests are applied mechanics, analysis of underground structures, and fusion technology in civil engineering.

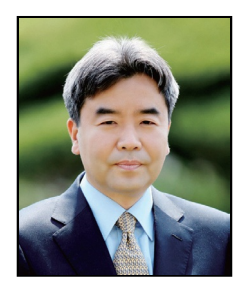

Han Kyu Yoo is working in Hanyang University at the faculty of civil and environmental system engineering at Ansan as a professor. His research interests are geotechnical and tunnel engineering. 